\title{
LA ESTRUCTURA URBANA EN LOS PROCESOS DE METROPOLIZACIÓN. Incidencia de las producciones habitacionales formales en la RMC en el período 2001-2017.
}

\author{
Autor: Schiavoni María Julia \\ Universidad Nacional de Córdoba. Facultad de Arquitectura Urbanismo y Diseño. \\ Director: Dra. Arq. Mónica Martínez
}

\section{RESUMEN}

Esta presentación es un primer avance del proyecto de tesis doctoral de beca interna doctoral CONICETCEUR dirigido por la Dra. Mónica Martínez y codirigido de la Dra. Cecilia Marengo, en el cual se aborda el tema-problema que presenta la estructura urbana en los procesos de metropolización, a partir de comprender la incidencia de la producción habitacional formal en centros urbanos pertenecientes a la Región Metropolitana de Córdoba (en adelante RMC) en el periodo 2001-2017.

En el contexto del subdesarrollo, se observa que las producciones habitacionales formales que se localizan en los centros urbanos que forman parte de una región metropolitana, lo hacen con una fuerte dependencia del centro polarizador, produciendo esto una distorsión en el sistema urbano, que incide en la estructura territorial, y complejiza las posibilidades de ordenamiento de la infraestructura, la vialidad y los servicios.

Se propone como objetivo central de investigación, comprender como inciden las urbanizaciones y el crecimiento de los centros urbanos en la estructura urbana y territorial de un sistema metropolitano.

Palabras Claves: Estructura urbana, producción habitacional, Región Metropolitana, Sierras Chicas.

\begin{abstract}
This presentation is a first step of the doctoral thesis project of the internal doctoral scholarship CONICETCEUR directed by Dr. Mónica Martínez and co-directed by Dr. Cecilia Marengo, in which the theme-problem is the urban structure in the metropolization processes, starting from understanding the incidence of formal housing production in urban centers of the Metropolitan Region of Córdoba (hereinafter RMC) in the period 2001-2017.

In the context of underdevelopment, it is recognized that the formal housing production that are located in urban centers in a metropolitan region, have a strong dependence on the polarizing center, producing a distortion in the urban system, which affects the territorial structure, and complicates the possibilities of ordering infrastructure, roads and services.

It is proposed as a central research objective, to understand how urbanizations and the growth of urban centers affect the urban and territorial structure of a metropolitan system.
\end{abstract}

Key Words: Urban structure, housing production, Metropolitan Region, Sierras Chicas. 


\section{INTRODUCCIÓN}

En el contexto del subdesarrollo, se observa que las producciones habitacionales formales que se localizan en los centros urbanos que forman parte de una región metropolitana, lo hacen con una fuerte dependencia del centro polarizador, produciendo esto una distorsión en el sistema urbano, que incide en la estructura territorial, y complejiza las posibilidades de ordenamiento de la infraestructura, la vialidad y los servicios. En este trabajo se estudia la incidencia de las producciones habitaciones formales tanto en la estructura urbana de los centros urbanos donde se localizan, como en la estructura territorial de la región metropolitana que participa.

Se estudian los centros conurbados del corredor Sierras Chicas dentro de la RMC, tomando como primer caso de estudio la localidad de Unquillo, ubicada a $27 \mathrm{~km}$ de la Ciudad de Córdoba. Estas localidades que se estructuran sobre la Rutas E-57 -hacia el camino del cuadrado-y E-53 -hacia Ascochinga, poseen una fuerte dinámica de conectividad vial y se caracterizan por el altísimo valor paisajístico ambiental, producto del sistema hídrico de los valles que conforman el territorio, en el cual la principal actividad de subsistencia está referida al turismo. Sus orígenes se dan a partir de asentamientos veraniegos, hoteles y segundas residencias.

Se propone como objetivo central comprender las transformaciones físicas producidas en la estructura urbana y metropolitana a partir de un enfoque multiescalar, verificando los cambios producidos en los centros urbanos a partir de la incidencia de las producciones habitacionales formales.

Se entiende por producción habitacional formal a las reglas de juego con las que se opera en la producción de vivienda. La modalidad de intervención del Estado está referida a partir de la implementación de planes tipo ABC (Ahorro, Bono y Crédito) y subsidios estatales, y desde el mercado inmobiliario a través de urbanizaciones privadas.

Se sostiene como hipótesis que las producciones habitacionales se ordenan territorialmente con dos lógicas: a) la lógica del territorio metropolitano que contiene los centros urbanos que forman parte de él b) la lógica del territorio urbano que conforman el conjunto de los centros de la región metropolitana. Esta doble pertenencia genera conflictos, que se acentúan según el tipo de producto habitacional, y su mayor o menor dependencia del centro urbano donde se localizan o de la región metropolitana que los contiene.

La ausencia de instrumentos de planificación, la desarticulación en los mecanismos de gestión entre los distintos niveles del Estado, las particularidades físicas de los modelos urbanos de las ciudades de la RMC, demuestra que los componentes físicos, sociales, políticos y económicos del territorio no son considerados en la producción habitacional, y como consecuencia, se producen cambios significativos en la estructura y dinámica urbana-territorial.

El desarrollo de esta presentación se organiza en: a) el desarrollo del marco teórico, b) el estudio del caso c) el reconocimiento de las variables que determinan el problema de investigación a estudiar.

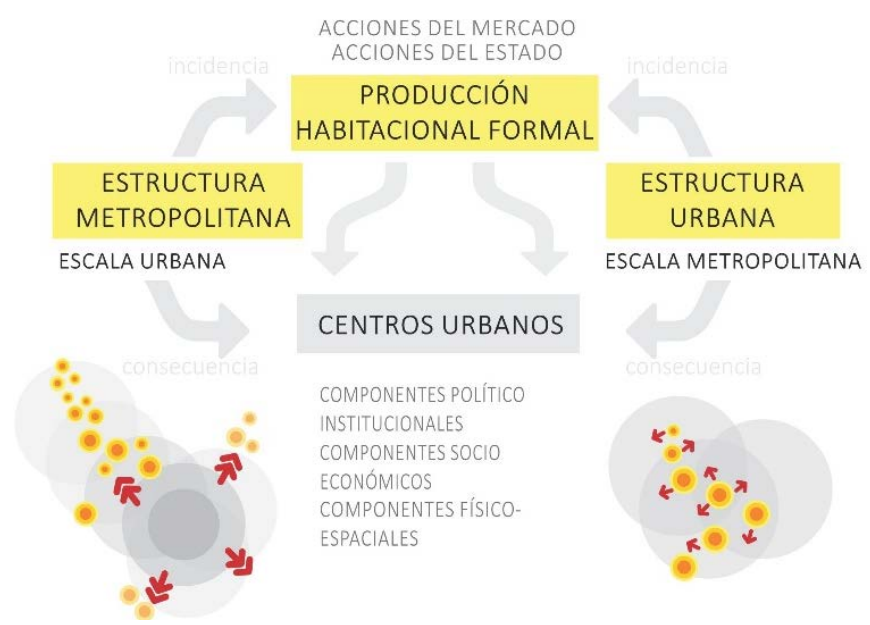

Gráfico 1. Esquema metodológico de abordaje de la investigación. Fuente: elaboración propia. 


\section{ENFOQUE TEÓRICO}

En los noventa el proceso de transformación económica del país, en particular la implementación de un modelo económico-político "neoliberal" planteó como primer problema a superar, el papel del Estado como regulador social. La "cuestión de la vivienda" en América Latina y particularmente en Argentina, se instala a partir de la problematización del nuevo fenómeno de la pobreza urbana y los Estados Nacionales ponen en marcha políticas habitacionales, centradas en programas de construcción de vivienda. ${ }^{1}$

El neoliberalismo sustenta la idea de que los mercados abiertos, competitivos y desregulados de la acción estatal y de cualquier colectivo social son el mecanismo óptimo para el desarrollo socioeconómico. ${ }^{2}$ Al respecto (Abramo, 2012) indica que este predominio del mercado como mecanismo de coordinación de las decisiones de uso del suelo, constituye un rasgo característico de éste tipo de ciudad.

En el marco de estas transformaciones, la economía Argentina se sumerge en una nueva organización económica, en la que existe una nueva división del trabajo entre el sector público y el privado. Se transfirieron desde el primero al segundo las actividades de producción de bienes y servicios cuya distribución es realizada a través de mecanismos de mercado (Cuenya y Falú, 1997). Estas transformaciones se perciben en el territorio, traduciéndose en diversas formas de actuación; inversiones en obras viales, vivienda y hábitat, infraestructura y equipamientos sociales.

Las políticas habitacionales se constituyen como los instrumentos del Estado para enfrentar las desigualdades tanto económicas como sociales. La modalidad de intervención del Estado, está referida al plano de la vivienda o hábitat según cómo sean enfocadas, y por lo tanto, se presentan como "un conjunto de acciones y omisiones que manifiestan en forma concreta la intervención del Estado en relación a la distribución/localización de los diferentes sectores y grupos sociales en la Ciudad y, concomitantemente, en relación a la satisfacción de necesidades habitacionales básicas" (Oszlak, 19913. En: Rodríguez et al; 2007: 24). ${ }^{3}$ Clichevsky (1996) profundiza en esta visión y aporta que el Estado apuesta a la zonificación de usos como mecanismo de control y de esta manera contribuye a espacializar la segregación residencial.

Las acciones implementadas en relación a la vivienda se evidencian en nuevas alternativas de desarrollo residencial, que mixturan barrios cerrados, conjuntos de vivienda social, asentamientos informales y villas, en un continuo/discontinuo de espacio urbano en áreas rurales, y centros menores en directa conurbación con ciudades de escala mayor que desatan fuertemente un fenómeno de metropolización, que, más allá del tamaño de la aglomeración y la forma urbana metropolitana se caracteriza por "la difusión de las actividades y funciones en el espacio y la interpenetración de dichas actividades según una dinámica independiente de la contigüidad geográfica". (Castells, 1976: 28).

En este contexto, aparece el interrogante central sobre el cual se inicia el abordaje de ésta problemática de estudio; que se plantea ¿Cómo se desarrollan los modelos urbanos a partir de intervención pública, privada y como incide esto en la producción de ciudad? y, ¿Porque la mayoría de las ciudades latinoamericanas actuales, presentan estructuras urbanas que no parecen funcionar ante las necesidades de su población? Muchos autores refieren a los diversos modelos de Ciudad y distintas corrientes de pensamiento que intentan explicar el fenómeno de la ciudad y su modelo de crecimiento, ¿pero será como dice Fernando de Terán en su libro, Problemas de forma y estructuras urbanas, que el problema está, en que no se pone en cuestión la configuración espacial, y todo es más un interés económico, social, o político? Rescato una frase de éste libro que opera como disparador de muchos interrogantes, que intentaré abordar en el desarrollo de la investigación. "Dejad que la ameba urbana vaya por donde le parezca; lo que realmente importa son las organizaciones económicas y sociales, y no las espaciales"...

\section{La estructura urbana y metropolitana}

En primer lugar se utiliza el término Región Metropolitana para definir el espacio geográfico mayor que contiene otras ciudades. Las situaciones de conurbación y metropolización asociadas al concepto de ciudad regional, definen una realidad compleja en donde necesariamente intervienen diferentes jurisdicciones locales. Como menciona Carlos de Mattos (1997) "el abordaje metropolitano trae aparejado el análisis de un espacio con múltiples procesos urbanos, un "proceso en el que la mancha metropolitana se expande en forma

\footnotetext{
${ }^{1}$ Metodología de intervención del Área Social del Instituto de la Vivienda de la Provincia de Buenos Aires (IVBA)- Plan Federal de Vivienda, Programa Construcción de Vivienda, operatoria llave en mano. Alumnas: Biglia, Marisa - Marsili, Inés - Vallina, Liliana

${ }^{2}$ La ciudad neoliberal y sus impactos en el territorio. María Cecilia Zapata. Recuperado en

https://www.teseopress.com/politicahabitacional/chapter/la-ciudad-neoliberal-y-sus-impactos-en-el-territorio/

${ }^{3}$ De espacialidades y políticas. La gestión de la ciudad de Córdoba en materia de políticas habitacionales y urbanas y su correlato territorial. Carla Eleonora Pedrazzani. Becaria CONICET/IIFAP/CEA/UNC.
} 
incesante, ocupando las áreas rurales que encuentra a su paso, desbordando los límites urbanos definidos en el momento anterior".

Tal como afirma Pírez (2005), las lógicas imperantes en el proceso de producción del espacio urbano están más cercanas a los intereses privados que a la orientación estatal. Esta argumentación encuentra su correlato en el análisis de Pedro Abramo (2003), al plantear que la producción de las ciudades modernas latinoamericanas resulta del funcionamiento de dos lógicas de coordinación social: la del mercado y la del Estado; pero también de una tercera: la lógica de la necesidad.

De acuerdo con (Abramo, 2012) quien afirma que el mercado, al ser el principal y hegemónico mecanismo de coordinación de las decisiones de uso del suelo, produce una estructura o forma de ciudad particular y característica de América Latina: una estructura "híbrida" desde el punto de vista de su morfología de usos del suelo, vis à vis los modelos tradicionales de la ciudad moderna. Esta ciudad tiene dos formas paradigmáticas, en términos materiales, la primera está identificada como el "modelo mediterráneo" o "continental" y su estructura urbana se configura como una ciudad "compacta", y la segunda responde al "modelo anglosajón" y su manifestación espacial es la ciudad "difusa". ${ }^{4}$ Esta última según (Janoschka, 2002) predominante en los modelos urbanos de las ciudades Latinoamericanas. Esta conceptualización de ciudad com-fusa que propone el autor, posibilitará abordar uno de los conceptos claves de investigación, la estructura urbana y metropolitana.

En la ciudad, el modelo urbano, representa de manera simplificada la configuración espacial de la estructura física que subyace en la ciudad. Se considera el modelo como una herramienta que simplifica diversos fenómenos urbanos, y que este no es más que la expresión conceptual de la estructura urbana.

Desde una corriente funcionalista, se considera que hay elementos y relaciones que componen el sistema urbano y su interés radica en describir las leyes sobre cómo se insertan las actividades en lugares específicos. Autores como Foley, Webber y más tarde, Yujnovsky, plantean que el objeto de estudio es el ordenamiento de las actividades en el espacio urbano. Para este enfoque, el aparente caos funcional sería un orden estructural y los estudios urbanos deben identificar esas estructuras para poder planificar o controlar el desarrollo urbano. ${ }^{5}$

La "estructura espacial" según (D. L. Foley 1970:17) tal como se expresa a través de su forma física, no es un sistema cerrado, sino que se trata de la estructura dentro de un contexto más amplio, "estructura espacial metropolitana". Abordar este enfoque, implica entonces afrontar el problema de la ordenación urbana refiriendo a aspectos "espaciales" e "inespaciales" entendiendo el primero como la distribución de los objetos físicos, y el segundo como la organización de las comunidades.

La estructura urbana, y metropolitana representan en términos "espaciales", el soporte físico en el que se materializa la ciudad, y en términos "inespaciales" la función particular -administrativa, política, social, económica- que cada núcleo constituye individualmente o en el conjunto, provocando "mutaciones" que tienen implicancias en la configuración del espacio.

Contrariamente dentro de la tradición clásica autores como Manuel Castells, David Harvey y Jean Lojkine, y dentro de América latina a Fernando H. Cardoso y Enzo Faletto, entienden que el espacio es considerado un producto o materialización de relaciones sociales. Es un producto de la relación sociedad-naturaleza. La producción del espacio urbano debe ser visto no sólo desde el ángulo del consumo sino de la producción, es decir, de las actividades necesarias para construir el espacio urbano. ${ }^{6}$

Manuel Castells, retoma el concepto de unidad ecológica como base material de la conformación del espacio urbano, pero la considera producto de las relaciones sociales que se dan en dicho espacio y en ese sentido, centra el análisis de la estructura urbana, como una conformación de 3 subsistemas: 1) el económico; 2) el político o de gestión y 3) el ideológico o simbólico. ${ }^{7}$

Por su parte (Terán, Fernando de, 1982) pone en discusión el papel de la planificación física y del diseño, atribuyendo que la corriente funcionalista aborda el estudio de la ciudad desde las organizaciones económicas

\footnotetext{
${ }^{4}$ Abramo, P. (2012). La ciudad com-fusa: mercado y producción de la estructura urbana en las grandes metrópolis latinoamericanas. EURE (Santiago), 38(114), 35-69.

${ }^{5}$ LA ESTRUCTURA URBANA - ENFOQUES CONCEPTUALES. Sin dato de autores. Disponible en http://ecaths1.s3.amazonaws.com/politicasurbanasmdp/1406698160.2012-09-18\%20-\%20La\%20Estructura\%20Urbana-

Aportes\%20Conceptuales.doc

${ }^{6}$ Ibídem

${ }^{7}$ Ibídem
} 
y sociales y no las espaciales, para lo cual propone encontrar una nueva vía metodológica para la planificación física y el diseño, a partir del análisis científico de la realidad en sus aspectos de forma y de estructura.

En este sentido propone un abordaje metodológico de estudio de componentes fundamentales para comprender y analizar la estructura urbana, entendiendo las relaciones entre la forma física de la ciudad y la distribución, organización y funcionamiento de las actividades dentro de ella.

Según (Terán, Fernando de, 1982) y en concordancia con la apreciación referida anteriormente, "la estructura, que es algo inmaterial, se refleja así en su proyección física, se materializa. Se identifica la estructura con algunos de los elementos físicos a través de los que se manifiesta. La simplificación consiste en asimilar la estructura a su proyección. Es una simplificación operativa que ayuda en la práctica, aunque sufra el rigor metodológico".

Otros autores como (Ducci 2003), y (Munizaga Vigil, 2000) proponen conceptualizaciones más vinculadas a una teoría física de análisis metodológico, entendiendo el concepto de que una estructura urbana presenta las zonas que componen un asentamiento humano, y son valoradas con base en los usos del suelo, y se constituyen por una serie de elementos físicos destinados a la realización de actividades distintas, cuya distribución determina la existencia de diferentes zonas en la ciudad con diferentes usos del suelo (habitación, industria, comercio y oficinas, vialidad y equipamiento).

En conclusión se trata de poner en evidencia, la existencia de numerosas fuentes y enfoques desde donde abordar teóricamente esta problemática y como los cambios en los modos de producción, en las comunicaciones, en las relaciones humanas, se traducen en nuevas actividades, nuevos medios de transporte, nuevos modos de vida. Conocer como la estructura física se adapta a éstos en la situación actual, y como podrá adaptarse frente a escenarios futuros, nos lleva a pensar y reflexionar, sobre estructuras posibles en escenarios cambiantes. ${ }^{8}$

\section{ESTUDIO DEL CASO}

\section{Estructura urbana y metropolitana. Unquillo en el sistema de las Sierras Chicas}

En el contexto planteado, se aborda el caso de estudio a partir de una primera construcción de la estructura urbana de la localidad de Unquillo en el contexto metropolitano. Desde un enfoque físico espacial ambiental, se describen los principales aspectos que caracterizan a la localidad de Unquillo en su contexto metropolitano. Este enfoque luego será atravesado a lo largo del desarrollo de la investigación, por la dimensión socioeconómica y político institucional, necesarias para obtener una mejor comprensión del objeto de estudio.

La Región Metropolitana de Córdoba, se extiende en un territorio aproximado de $80 \mathrm{Km} 2$, del cual se desprenden 82 localidades con una superficie de aproximadamente $7.854 \mathrm{~km} 2$ y una población de 1.468 .842 habitantes, distribuidos en 30 Gobiernos locales pertenecientes a 5 departamentos (Colón, Río Segundo, Punilla, Santa María y Río Primero) ${ }^{9}$

La estructura metropolitana del corredor Sierras Chicas, evidencia el desarrollo de una serie de centros urbanos que poseen fuerte interacción con la ciudad de Córdoba, conformando una conurbación de ciudades que se organizan en diferentes tipos de estructura urbana, compartiendo similares características en relación al medio físico espacial, socio-económico y político institucional.

\footnotetext{
${ }^{8}$ Articulo elaborado por la Dra. Mónica Martínez, docente adjunta a cargo de la Catedra de Urbanismo $1 \mathrm{~A}$ e investigadora de la Facultad de Arquitectura, Urbanismo y Diseño de la Universidad Nacional de Córdoba.

${ }^{9}$ Periurbanización y metropolización, desafíos y cuestiones críticas en el Área Metropolitana Córdoba. Claudio A. Tecco. Administración Pública y Sociedad
} 


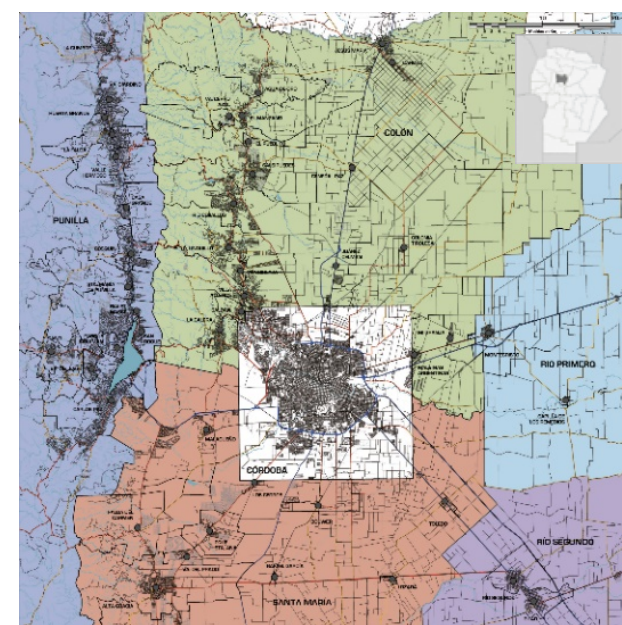

Región metropolitana de Córdoba. División departamental, Colón (en verde), Río Segundo, Punilla, Santa María y Río Primero. Fuente: IPLAM Provincial.

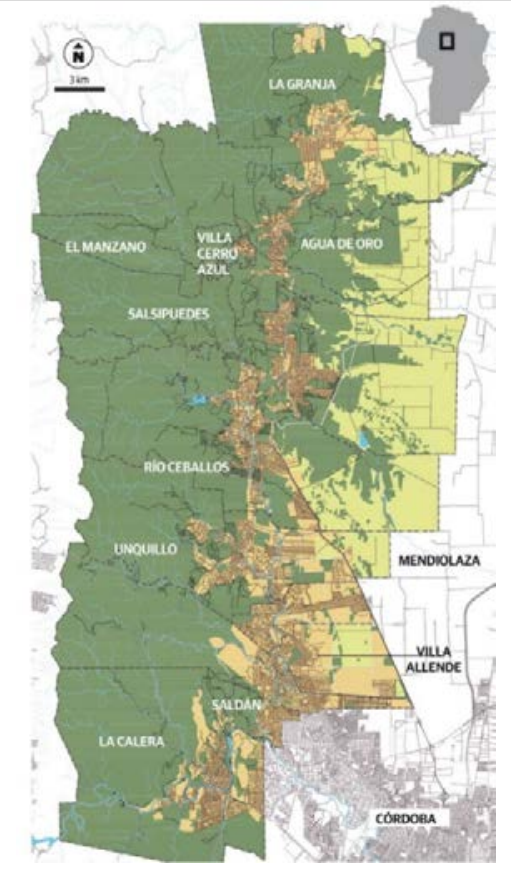

Territorio de estudio. Sistema de Sierras

Chicas y localidades que lo componen.

Fuente: IPLAM Provincial.

Gráfico 2. Territorio de estudio y localidades pertenecientes al corredor Sierras Chicas. Fuente: elaboración propia.

\section{Localización y Medio Natural}

La Ciudad de Unquillo se localiza dentro del corredor Sierras Chicas; un amplio territorio ubicado en el cuadrante Noroeste de la RMC de Córdoba en el Departamento Colón el cual se extiende por la ladera oriental de la Sierras Chicas y por la llanura pampeana. La localidad está ubicada a $27 \mathrm{~km}$ de la ciudad Capital y se constituye como una de las localidades más importantes dentro del corredor con una población, según censo de población, hogares y viviendas de 2010, de 18.483 habitantes y una densidad promedio (según censo 2010 y ejido pretendido) es de 4.13 habitantes/ha. Esto representa una Ciudad de extenso territorio con baja ocupación poblacional. El ejido pretendido de la localidad es de 8666 ha, de las cuales un $50 \%$ corresponde a la Reserva Hídrica, Natural y Recreativa Los Quebrachitos, uno de los atractivos más interesantes de la localidad.

El territorio geográfico de las Sierras Chicas, se caracteriza por la presencia de numerosas reservas naturales, que otorgan un altísimo potencial paisajístico ambiental. Su caracterización geomorfológica responde a la zona de transición del piedemonte, en donde predomina un paisaje de bosquecillos y pastizales. El sistema hidrológico de este corredor, se compone a través de las cuencas de los Ríos Ceballos y Saldán, que drenan por la ladera oriental de las Sierras Chicas y constituyen la principal fuente de abastecimiento de agua para consumo humano y recreación en las ciudades de la zona.

Esta cuenca es una de las que posee mayor extensión de bosques serranos en buen estado de conservación dentro de la provincia de Córdoba, pero según estudios de la Universidad Nacional de Córdoba, más de un tercio de su superficie ha perdido su cobertura natural como resultado de la explosión urbana y el cambio en el uso del suelo, mientras que otro tercio ha perdido cobertura boscosa debido a los reiterados incendios que afectaron esa zona. ${ }^{10}$

Unquillo se asienta sobre un territorio cuya topografía se caracteriza por importantes y marcados desniveles. Hacia el Oeste se localizan las zonas de mayores pendientes, la cota 750 sobre el nivel del mar, separa la zona no urbanizable del área urbanizable, mientras que hacia el Este se desarrollan las actividades productivas de la localidad. En los últimos años se ha evidenciado un importante crecimiento urbano hacia las zonas de montaña, sector Oeste, impactando la urbanización de manera directa sobre uno de los

\footnotetext{
${ }^{10}$ Los cambios de usos del suelo -y sus efectos pérdida de cobertura, transformación de los ecosistemas- son consecuencia de los usos urbanos, agropecuarios, mineros, siendo estos uno de los principales factores de degradación del planeta, de producción de desastres ambientales, y del cambio climático mediante acumulación de anhídrido carbónico. Fuente: En revista Tecyt-Taller de Estudios de la Ciudad y el Territorio. Riegos ambientales ante el cambio de usos del suelo en Sierras Chicas. Dra. Alicia Barchuk P.p 26.
} 
atractivos turísticos naturales más importantes de la localidad; la Reserva Hídrica, Natural y Recreativa Los Quebrachitos.

El sistema hídrico de la localidad se compone por 5 cursos de agua, los arroyos Cabana y Las Ensenadas provenientes de la zona de montaña, confluyen en la zona céntrica originando el arroyo Unquillo, que continúa hacia el Este y se encuentra con el Río, Río Ceballos-Saldan. Gran parte del centro histórico de la Ciudad, como algunos sectores suburbanos, ocupan el nivel inferior de terraza inundable en forma total en crecidas ordinarias máximas, lo que significa un riesgo de consideración, que se torna severo ante la ocurrencia de crecidas históricas.

\section{Población y Proceso de Ocupación}

Los primeros antecedentes de ocupación del corredor se vinculan a la extracción de cales y piedra de sus yacimientos, los cuales permitían la construcción en la Ciudad y la región, dando lugar a los primeros edificios fundacionales, los grandes monumentos históricos, molinos hidráulicos, y una gran variedad de edificaciones que dieron inicio al desarrollo de la zona. Con la llegada de los Jesuitas en el siglo XVII, se instalan en la zona numerosas estancias y capillas que dieron origen a los primeros pobladores de la zona, instalados en establecimientos donde primaba la producción agraria y ganadera, generando un importante volumen de intercambio comercial.

A principios del Siglo XX se encuentran los orígenes de la localidad Unquillo, en 1913 el Ministerio de Obras Públicas de la Nación reconoció con el nombre de Unquillo a la estación del Ferrocarril Central Argentino, ubicada en el kilómetro 17,92. Aunque en el lugar ya existían otras construcciones y el paraje estaba poblado, ese hecho histórico fue el mojón que se toma como punto de partida de lo que hoy es una de las ciudades más grandes de las Sierras Chicas. ${ }^{11}$

A partir de 1870, con la llegada de Ferrocarril, la vinculación de la Ciudad de Córdoba con Sierras Chicas se concreta con la inauguración del ramal $\mathrm{CC}^{12}$ que se desprendía del FFCC Belgrano al Norte, en la estación Guiñazú, hasta Río Ceballos, pero que solo llegaría a Unquillo. Este servicio generó una gran expectativa en las familias de la Ciudad de Córdoba, quienes adquirían terrenos importantes y construían casas de veraneo aprovechando las excelentes condiciones del medio natural.

Entre el siglo XIX y comienzos del XX, Sierras Chicas crece en un contexto de acelerado desarrollo por la dinámica que generaron las grandes obras de infraestructura como la construcción del dique San Roque, el Mal Paso, los canales de riego y usinas hidroeléctricas, a las que se sumó la compañía Sud Americana de cemento Portland S.A. de Juan Minetti, convirtiendo el original ambiente rural de producción agrícola, en desarrollo y progreso.

Según un estudio encomendado al Iffap en 1998, el 63 \% de la población de este municipio, no es originario de dicha localidad y más del $60 \%$ de dicho grupo se radicó allí durante los últimos 15 años. A su vez el $45 \%$ de estos "nuevos unquillenses" proceden de la ciudad de Córdoba. Asimismo, el 34\% de la población activa ocupada de Unquillo trabaja en la ciudad de Córdoba; destino éste al que el $40 \%$ de los habitantes de la localidad viaja al menos una vez por semana." ${ }^{13}$

A comienzos de los noventa, las localidades suburbanas, comenzaron a tener un ritmo de crecimiento mayor al de la Ciudad de Córdoba. Los nuevos pobladores, de clases socio económicas medias, eligieron este territorio por la accesibilidad en el precio del suelo urbano, y la diversidad paisajística de su territorio.

En las últimas décadas, el corredor experimentó significativos cambios en su estructura demográfica, reflejando un crecimiento poblacional en el departamento Colón entre 2001 y 2010 del 31,6\%, ${ }^{14}$ convirtiéndose en el departamento que más creció en la última década.

\begin{tabular}{|c|c|c|c|c|c|}
\hline LOCALIDAD & DEPTO & TIPO & \multirow{2}{*}{$\begin{array}{c}\text { POBLACIÓN CENSO } \\
1991 \text { (hab) }\end{array}$} & \multirow{2}{*}{$\begin{array}{c}\text { POBLACIÓN CENSO } \\
2001 \text { (hab) }\end{array}$} & \multirow{2}{*}{$\begin{array}{c}\text { POBLACIÓN CENSO } \\
2010 \text { (hab) }\end{array}$} \\
\hline & & & & & \\
\hline Saldán & Colón & Localidad urbana & 1.868 & 2.099 & 10.605 \\
\hline Villa Allende & Colón & Localidad urbana & 16.025 & 21.683 & 25.738 \\
\hline
\end{tabular}

\footnotetext{
${ }^{11}$ Recuperado en; http://www.lavoz.com.ar/regionales/unquillo-cumple-los-100-pero-con-siglos-de-historia.

12 Desarrollo preliminar del plan director de Sierras Chicas. Iplam Metropolitano.

${ }^{13}$ Propuesta lineamientos de intervención Urbano Ambiental Participativo para Unquillo.

${ }^{14}$ Periurbanización y metropolización, desafíos y cuestiones críticas en el Área Metropolitana Córdoba. Claudio A. Tecco.

Administración Pública y Sociedad
} 


\begin{tabular}{|l|l|l|r|r|r|} 
Mendiolaza & Colón & Localidad urbana & 1.536 & 4.204 & 10.271 \\
\hline Unquillo & Colón & Localidad urbana & $\mathbf{1 1 . 6 9 3}$ & $\mathbf{1 5 . 3 6 9}$ & 16.632 \\
\hline Río Ceballos & Colón & Localidad urbana & 12.802 & 6.411 & $\mathbf{1 8 . 0 8 6}$ \\
\hline Salsipuedes & Colón & Localidad urbana & 4.087 & 289 & 19.688 \\
\hline Canteras el Sauce & Colón & Localidad urbana & 483 & 869 & 9.612 \\
\hline El Manzano & Colón & Localidad Urbana & 161 & 190 & 290 \\
\hline Villa Cerro Azul & Colón & Localidad Rural & 119 & 1.553 & 892 \\
\hline Agua de Oro & Colón & Localidad Urbana & 923 & & 253 \\
\hline
\end{tabular}

Tabla con datos de población localidades corredor Sierras Chicas. Elaboración propia en base a Censo Nacional de Población, Hogares y Viviendas 2010

\section{Vialidad y Usos del Suelo}

La Red vial metropolitana representa un esquema radial de anillos que conectan la ciudad de Córdoba con las localidades periféricas. Las localidades de las Sierras Chicas, se estructuran sobre la Rutas E-57 -hacia el camino del cuadrado-y E-53 -hacia Ascochinga. Estas rutas pertenecientes a la red de accesos a la Ciudad de Córdoba, participan fuertemente de la dinámica metropolitana, y determinan un rol predominante de asentamientos turísticos, y ciudades dormitorios originadas a partir de asentamientos veraniegos, hoteles y segundas residencias.

A nivel regional esta red principal se complementa con otras vías importantes que se estructuran transversalmente a estos corredores. En la localidad de Villa Alende las intermunicipales RP S/N Av. Padre Luchesse y la Intermunicipal Villa Allende-Unquillo, en Mendiolaza, la Av. Tissera, en Unquillo el camino provincial S-441- Amadeo Sabattini, y en Río Ceballos por la calle Remedios de Escalada en dirección a Camino del Cuadrado.

La estructura viaria de la Ciudad de Unquillo se ordena a partir estos corredores regionales. La RP N ${ }^{\circ}$ E-53 se constituye como un límite físico de gran importancia y opera como un borde tanto de movilidad y desarrollo urbano por la presencia de nuevas urbanizaciones que se extienden a lo largo del corredor. La misma carece de servicios e infraestructura básica, pero opera como un fácil articulador para el acceso a la localidad, a partir del camino provincial S-441- Amadeo Sabattini, que atraviesa en sentido Este-Oeste la ciudad de Unquillo y se conecta con esta ruta. Este camino se encuentra en proceso de consolidación. La rápida salida a la ciudad de Córdoba, la presencia de nuevos proyectos a nivel local y provincial (puentes viales y desarrollos urbanísticos) y la sistematización del corredor a través del segundo anillo de circunvalación del Plan Vial Metropolitano aprobado por la Ley provincial № 9687 , son factores que demuestran su evidente crecimiento a nivel local y regional.

El flujo de tránsito registrado en el corredor, según datos de peajes de la Concesionaria Caminos de las Sierras SA, es el segundo en importancia de la RMC, concentrando el $22 \%$ del total del tránsito. El aumento de tránsito más marcado en la RAC corresponde a la Ruta Provincial E53, donde la demanda se ha duplicado en el período con tasas medias interanuales por encima de los valores promedio. ${ }^{15}$

El importante desarrollo vial del corredor, ha impulsado principalmente en las últimas décadas un importante crecimiento urbano que se refleja en los usos del suelo y en el avance de la urbanización residencial principalmente de inversión privada.

La ley provincial de usos del suelo № 9841 regula los usos del suelo en la región metropolitana de córdoba. El espacio metropolitano presenta diferentes tipologías, dentro de las que predomina el uso residencial y Agropecuario conformado un anillo irregular, compuesto por "mosaicos" de diverso tipo, entre los cuales existen superficies vacías cuyos propietarios especulan con el futuro de dichos suelos. ${ }^{16} \mathrm{El}$ uso de suelo industrial se presenta de manera muy aislada y se localizan principalmente sobre los corredores de las rutas E-57 y E-53, en áreas más próximas a la ciudad de Córdoba, y corresponden principalmente a industrias agroalimentarias.

\footnotetext{
${ }^{15}$ Análisis y correlación de los procesos de urbanización y la infraestructura física - el sistema de transporte. Caso: Eje Sierras Chicas Área Metropolitana Córdoba R.A. Centro de Estudios de Planeamiento y Territorio (CEPLAT) Facultad de Ciencias Exactas Físicas y Naturales. Universidad Nacional de Córdoba.

${ }^{16}$ Periurbanización y metropolización, desafíos y cuestiones críticas en el Área Metropolitana Córdoba. Claudio A. Tecco.
} 
El uso del suelo predominante en la localidad es el residencial, complementándose sobre las vías más importantes con usos comerciales de diversas escalas. La zonificación de usos del suelo dispuesta en la ordenanza 825/2014, prevé ordenar y orientar el crecimiento con objetivos de proteger el soporte natural y paisajístico, y regular el crecimiento, promoviendo un mayor desarrollo hacia las áreas más consolidadas de la localidad.

Hacia la zona de la Ruta provincial E-53 se localizan los usos agropecuarios e industriales. Por mencionar algunos de ellos, se encuentran el ex frigorífico Estancias del Sur, algunas actividades pecuarias, cría de aves y animales, y otras relacionadas a la siembra de maíz y soja. Estas actividades producen impactos negativos, y producen usos conflictivos entre residencia, industria y producción rural.

La fuerte y rápida expansión del territorio municipal, principalmente a partir de los corredores viales regionales, tiende a concentrar algunas actividades de gran inversión privada. Sobre la RP E-53 se localizan grandes equipamientos de servicio y consumo. Hoteles internacionales, el aeropuerto Internacional Ambrosio Taravella, nuevas áreas de comercialización (hipermercados y shoppings centers), Universidades privadas, Ciudades empresariales y una gran oferta de urbanizaciones cerradas. La dinámica de estos grandes equipamientos promovió una gran cantidad de entidades educativas, de salud, centros comerciales y otros servicios que se fueron instalando en la zona. Si bien a nivel local Unquillo, y los demás centros, cuentan con una amplia cobertura de equipamientos educativos, sanitarios y culturales que cubren la demanda local, a través de instituciones públicas y privadas, no logran una autonomía, por la fuerte conexión con la ciudad polarizadora.

\section{Infraestructura y Servicios}

El sistema urbano de las sierras chicas, registra déficits en la cobertura de infraestructura, principalmente por la presión del mercado inmobiliario, que ante la falta de regulación y la carencia de normas a escala metropolitana, demuestran que la producción de vivienda avanza sobre los recursos disponibles para la urbanización. Como ejemplo de esta problemática se pueden citar déficits de abastecimiento de agua al verse superada la oferta natural del recurso, la falta de infraestructura de gas natural, así como algunos inconvenientes de congestión y seguridad en la infraestructura vial.

En tanto la localidad de Unquillo la Red de Agua es gestionada por la Cooperativa de Agua y Servicios públicos de Unquillo y Mendiolaza Ltda. Existen áreas sin cobertura, sobre todo hacia el Este de la localidad en dirección a la Autovia E-53. En cuanto a la red de Gas Natural, Unquillo no cuenta con este servicio, pero actualmente el proyecto de se encuentra en proceso de licitación. El mismo prevé un gasoducto que llega desde Colonia Tirolesa, ingresando a la localidad por el área del frigorífico Estancias del Sur aproximadamente. La obra de gas está ligada al mejoramiento de la infraestructura vial, ya que se considerará su pavimentación a posterior del zanjeado. Se prevé la construcción de la red para conexiones domiciliarias. ${ }^{17}$

\footnotetext{
${ }^{17}$ Propuesta lineamientos de intervención Urbano Ambiental Participativo para Unquillo.
} 


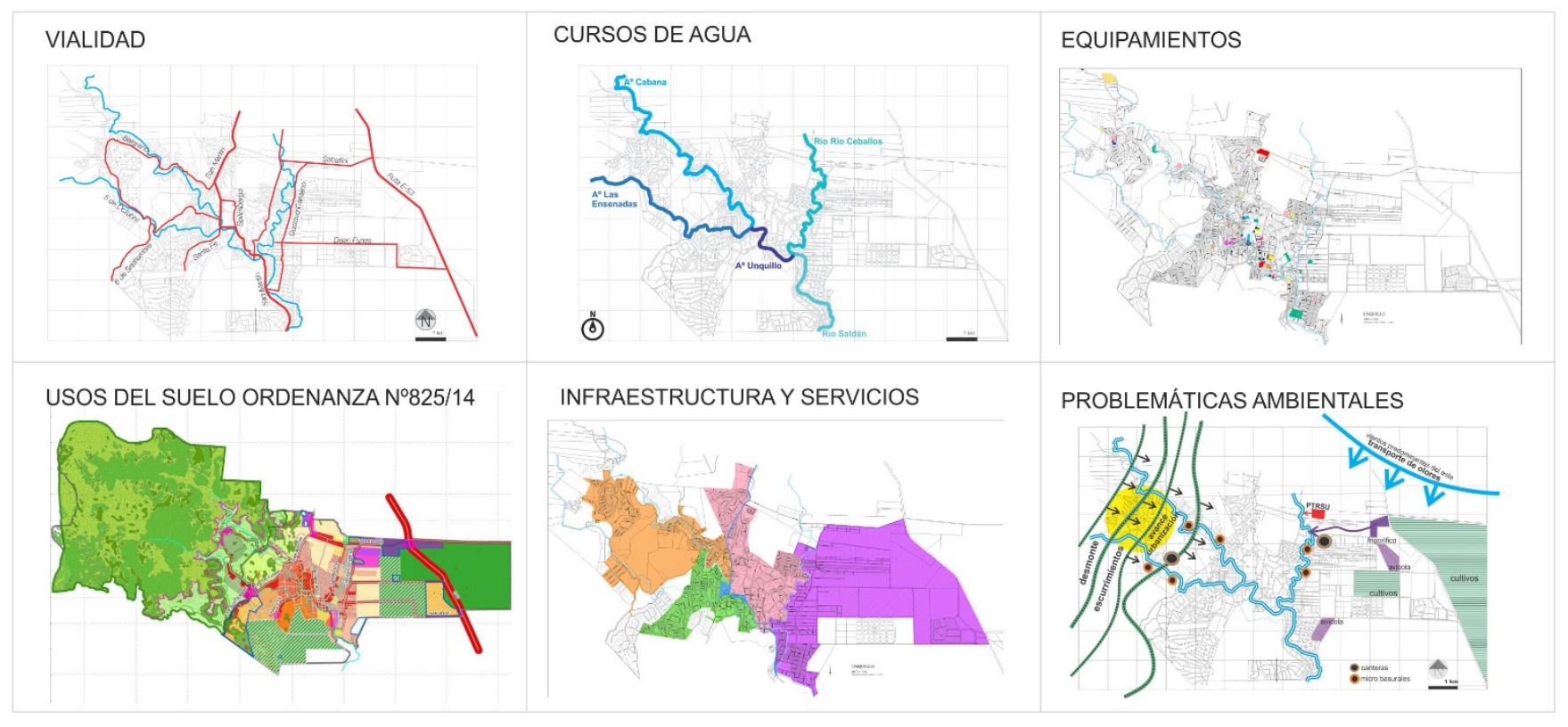

Gráfico 3. Estructura Urbana Unquillo del caso de estudio. Fuente: elaboración propia en base a mapas área de planeamiento Urbano, Localidad de Unquillo.

\section{PRODUCCIONES HABITACIONALES. UN SISTEMA DE RELACIONES URBANO-TERRITORIALES}

En el contexto del subdesarrollo, se observa que las producciones habitacionales formales, en adelante (PHF), que se localizan en los centros urbanos que forman parte de una región metropolitana, lo hacen con una fuerte dependencia del centro polarizador, produciendo esto una distorsión en el sistema urbano, que incide en la estructura territorial, y complejiza las posibilidades de ordenamiento de la infraestructura, la vialidad y los servicios.

El término producción hace referencia a la actuación de diferentes actores sociales sobre el territorio, y se indaga sobre la formalidad urbana, como un modelo de ocupación y uso del espacio urbano, en el que se invierten recursos para la producción de ciudad.

Se entiende por producción habitacional formal a las reglas de juego de gestión pública y privada con las que se opera en la producción de vivienda. La modalidad de intervención del Estado está referida a la implementación de planes tipo ABC (Ahorro, Bono y Crédito) y subsidios estatales, y desde el mercado inmobiliario a través de urbanizaciones privadas.

La modalidad del Estado tiene por objetivo, como se indica en el Art. № 58 de la Constitución de Córdoba, promover el acceso efectivo a la vivienda digna mediante la implementación de políticas que promuevan un desarrollo urbano con mayor equidad social, eficiencia urbana y sostenibilidad ambiental.

En este marco, la producción pública impulsada por el Gobierno de la Provincia de Córdoba desarrolló algunos emprendimientos en el corredor Sierras Chicas como, el "Plan Vida Digna" que contempla la asistencia económica a familias en situación de vulnerabilidad, el plan "Córdoba de Pie" en respuesta a las últimas inundaciones que afrontó RMC, en donde la secretaría de Vivienda construye actualmente 156 viviendas en distintas localidades de Sierras Chicas, 50 en Río Ceballos, 80 en Villa Allende, ocho en Mendiolaza y 18 en Unquillo. A nivel Nacional el Procrear tuvo un gran protagonismo en la promoción de vivienda, y las localidades Serranas fueron el lugar predilecto de emplazamiento. Este programa representó el boom del crecimiento urbano generando nuevos asentamientos -barrios y sectores urbanos completamente ocupados por viviendas del plan-.

La modalidad del mercado inmobiliario, antepone como objetivo la rentabilidad del suelo y la vivienda, y aborda diferentes y modernas tipologías de intervención. Las acciones de promoción privada son comparativamente mucho mayores a las de gestión pública. Estas urbanizaciones representan la conformación de islas de grandes dimensiones, con pequeños fraccionamientos internos, que difieren de las características formales del resto de la ciudad, promoviendo un crecimiento, aleatorio y fragmentado. 
A partir de observaciones, relevamiento e información de actores claves, se sostiene como hipótesis que las producciones habitacionales se ordenan territorialmente con dos lógicas: a) la lógica del territorio metropolitano que contiene los centros urbanos que forman parte de él b) la lógica del territorio urbano que conforman el conjunto de los centros de la región metropolitana. Esta doble pertenencia genera conflictos, que se acentúan según el tipo de producto habitacional, y su mayor o menor dependencia del centro urbano donde se localizan o de la región metropolitana que los contiene.

La localización de las producciones habitacionales sería una de las causas de la conflictividad de usos y relaciones, del excesivo consumo de suelo urbano y del crecimiento difuso de las ciudades y los territorios, en el contexto de la metropolización.

\section{Intervenciones sobre el espacio metropolitano y urbano}

Como se mencionó anteriormente, a partir del año 1970 las localidades de la RMC presentaron tasas de crecimiento anual intercensal superiores a las de la ciudad capital. Según (Marengo 2013), la variación relativa del crecimiento poblacional intercensal para el departamento de Colón en el período 2001-2008 es de 21,7\%, mientras que para el departamento capital (municipio de Córdoba) es de 2,4\%. Estos datos se reflejan en los precios de mercado, en donde el calor del suelo en la RMC es hasta 5 veces menores que en la Ciudad de Córdoba. ${ }^{18}$

En términos generales, éste crecimiento responde en su gran mayoria a urbanizaciones operadas por el mercado inmobiliario. Durante las últimas décadas este tipo de intervenciones han dinamizado el corredor Sierras Chicas, bajo la modalidad de barrios abiertos. Se registra que el $25 \%^{19}$ de la población vive en este tipo de urbanizaciones, las cuales ofrecen servicios similares a los cerrados, con ingreso controlado, cercado perimetral, barreras vehiculares e instalaciones deportivas y sociales internas.

El procedimiento que da origen a estas urbanizaciones comienza con la compra de tierras de uso productivo de baja rentabilidad y de escaso valor en el mercado, clasificadas en su mayoría como de uso rural o semirural. Luego, con el cerramiento, parcelación del terreno e instalación de servicios, se pasa a un uso urbano residencial, ingresando así al mercado inmobiliario como urbanizaciones destinadas para sectores socioeconómicos medios y medio-altos. ${ }^{20}$

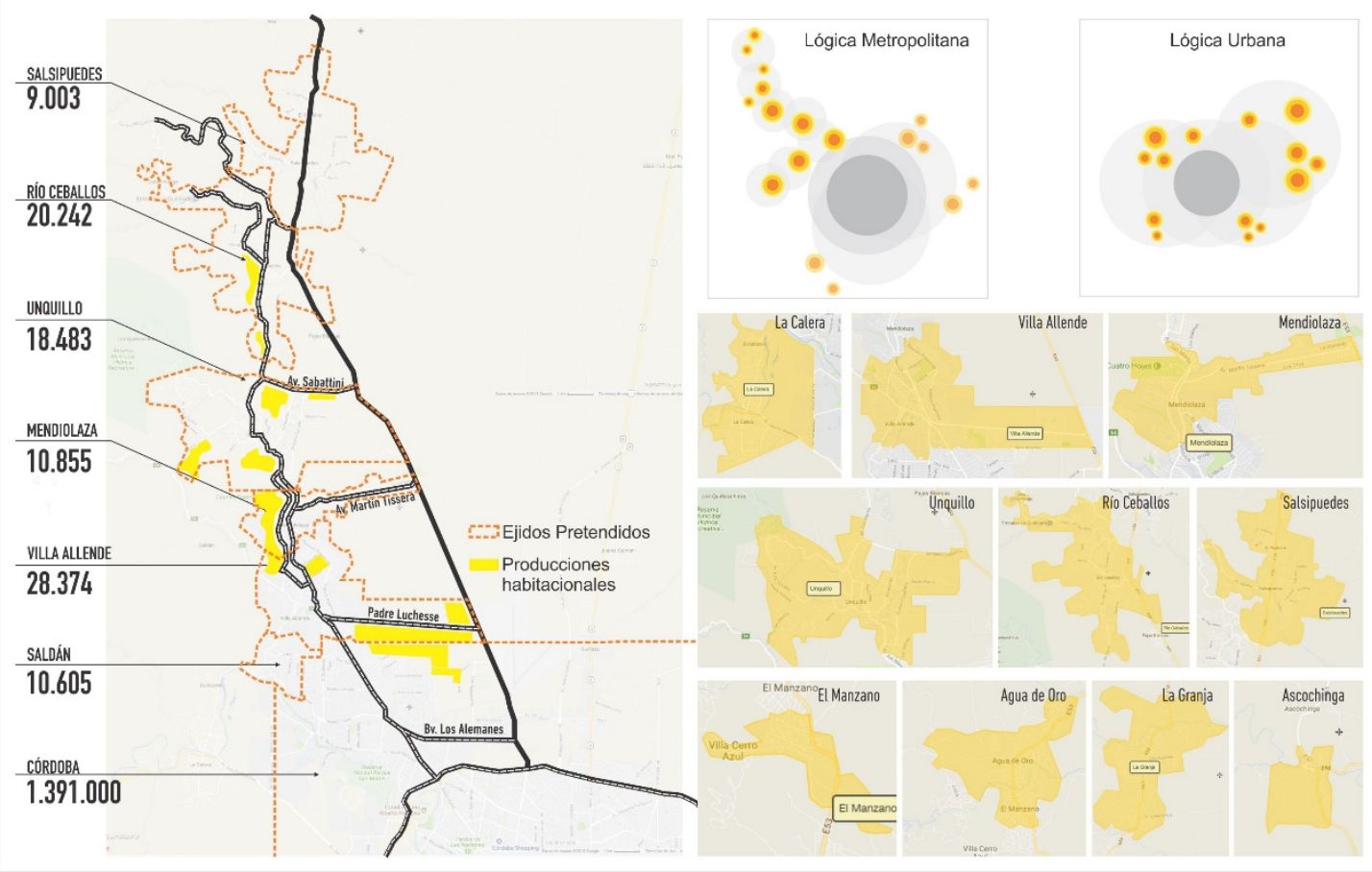

\footnotetext{
${ }^{18}$ Extensión urbana e intervenciones habitacionales. El caso de la ciudad de Córdoba (Argentina). Marengo Cecilia. 2013

${ }^{19}$ Información extraída del diario La Voz del Interior. A medida que la investigación se desarrolle, se tomaran datos y muetras especificas para el ajuste de datos.

${ }^{20}$ Expansión del espacio urbano. Análisis de elementos conceptuales en el estudio de la Región Metropolitana de Buenos Aires. Ezequiel Acsebrud, Gonzalo Barrios García y Victoria D’hers. 2015
} 
Gráfico 4. Esquema de intervenciones sobre el espacio metropolitano y urbano. Localidades de estudio Fuente: elaboración propia, en base a observaciones y trabajo de campo.

En este contexto la ciudad de Unquillo ha crecido de manera acelerada en los últimos años, este crecimiento se evidencia en la ocupación del territorio y la extensión de la mancha urbana. La producción residencial evidencia a priori, dos formas predominante de ocupación, por un lado hacia el sector Oeste, la vivienda individual privada, y algunos conjuntos habitacionales, que impactan directo sobre el suelo natural protegido, y por otro, hacia el Este, zona productiva de la localidad, una gran cantidad de urbanizaciones y loteos privados y estatales que conviven entre incompatibilidad de usos y carecen de infraestructura y servicios básicos

Históricamente este centro urbano, al igual que los de su corredor, originados a partir de asentamientos espontáneos no contemplaban normas de ocupación, con lo cual se la ciudad comenzó a expandirse hacia estos sectores urbanos, configurando un territorio heterogéneo y muy disperso, dejando a merced del Estado y del privado, bolsones intersticiales con distintos grados de consolidación posibles de ser urbanizados.

Se reconocen al menos cuatro patrones de asentamiento; desde el ámbito estatal, a-planes de vivienda, y desde el ámbito privado b- Urbanizaciones Cerradas, c-Grandes proyectos de urbanización, d- Proyectos de Urbanización en proceso de consolidación.

De estas categorizaciones resultan numerosos polígonos inconexos entre sí y con la ciudad formal. Las intervenciones en la estructura de la ciudad se constituyen más bien como una sucesión de núcleos aislados escasamente vinculados al trazado urbano existente, las localizaciones son producto de suelo disponible sin regulación, los espacios públicos son el resultado de parcelas residuales de los proyectos de urbanización, y tanto la movilidad como la oferta y acceso a equipamientos y servicios es deficiente.

Si bien a través de algunos lineamientos normativos, se perciben esfuerzos por integrarlos a la trama urbana existente, otros condicionantes físicos, propios de territorios de morfología irregular, y la propia especulación del privado, impide un crecimiento ordenado y pautado para la protección del medio natural y construido.

Estas lógicas de ocupación generan distintos patrones de asentamiento y modos de apropiación y ocupación, lo que inducen a abordar los modos de producción del espacio residencial, a partir del reconocimiento de las variables localización y distancia, consumo de suelo urbano, producciones habitacionales, marco político institucional, mercado de suelo y criterios de planificación, con el objetivo de demostrar las incongruencias o incompatibilidades entre los procesos de expansión metropolitana (y su laxa o débil planificación estatal) y los criterios de planificación urbana que todavía prevalecen en las administraciones locales sobre las que se produce aquella expansión, a menudo contra los criterios locales.

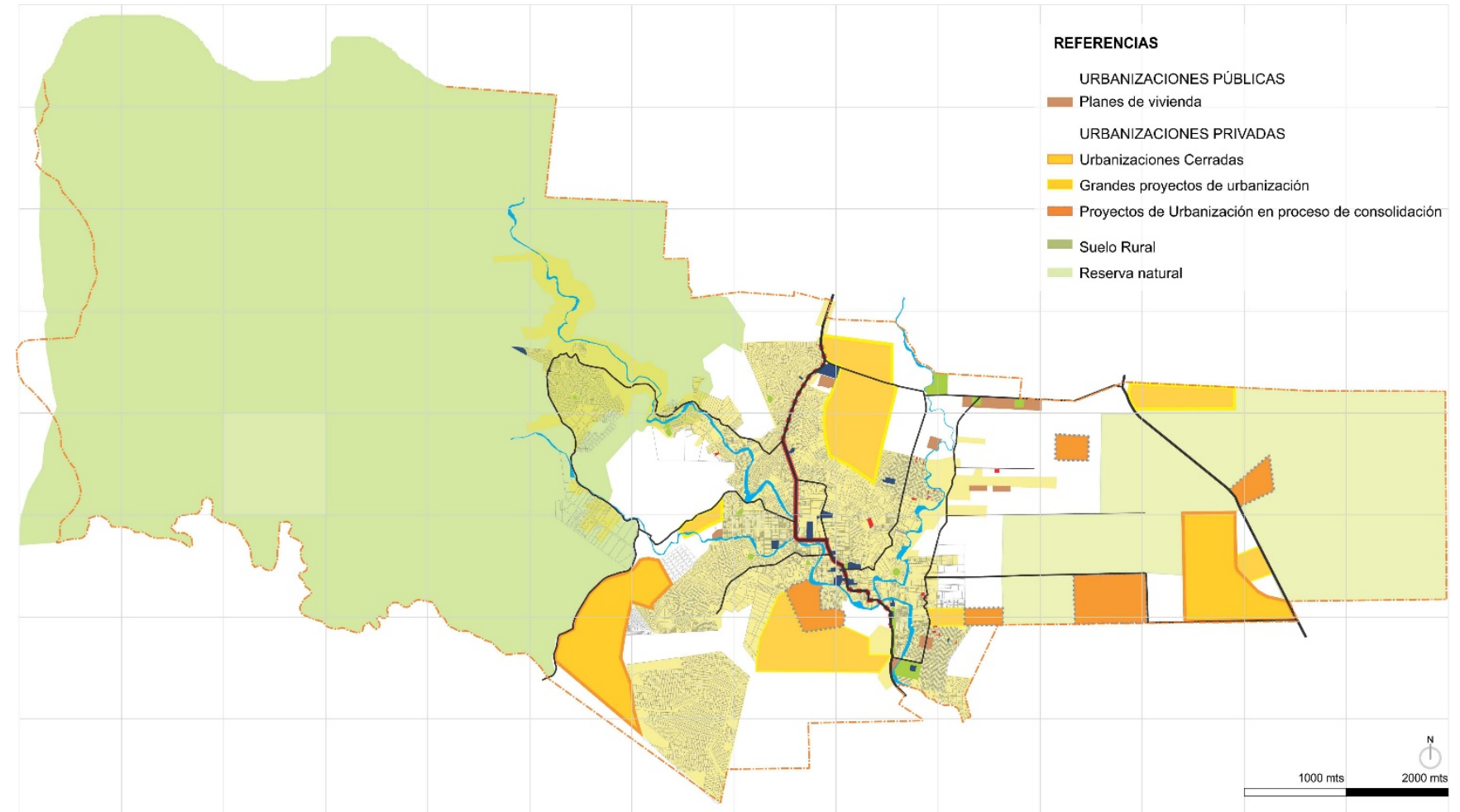


Gráfico 5. Patrones de asentamiento. Urbanizaciones Públicas y privadas registradas en la localidad de Unquillo hasta el año 2017. Fuente Elaboración propia en base a fuentes Municipalidad de Unquillo.

\section{CONCLUSIONES}

A partir de las consideraciones abordadas en la presente ponencia, se estima que la falta de instrumentos de planificación, la desarticulación en los mecanismos de gestión entre los distintos niveles del Estado, las particularidades físicas de los modelos urbanos de las ciudades de la RMC, demuestra que los componentes físicos, sociales, políticos y económicos del territorio no son considerados en el diseño de las políticas implementadas y como consecuencia, se producen cambios significativos en la estructura y dinámica urbanaterritorial.

Desde el componente físico, las localidades receptan demandas que exceden la oferta de los municipios; ausencia de suelo urbano para nuevas urbanizaciones, carencia de marcos regulatorios y normativos obsoletos, servicios de infraestructura parciales o inexistentes, entre otros.

Desde el componente social, las políticas de planificación no siempre dan respuesta a las necesidades de la población. La explosión urbana provoca diversos modos de ocupación en el territorio dando lugar a un desorden urbano.

Desde el componente político, las acciones de los diferentes niveles del estado, registran un doble juego, evidencian voluntad redistributiva, mientras que operan en la economía beneficiando a determinados sectores y agudizando los efectos negativos de un mercado de suelo sin regulación.

Desde el componente económico, el valor del suelo privado urbano está distorsionado y sin regulación y la oferta de suelo no es accesible para los diversos grupos sociales.

Resulta central avanzar en la construcción de una estructura territorial, no estática sino capaz de soportar acciones de cambio, estrategias de desarrollo y lógicas de ocupación acordes a las nuevas demandas en el marco de procesos planificados.

\section{BIBLIOGRAFÍA}

- $\quad$ ABRAMO, P. (2012). La ciudad com-fusa: mercado y producción de la estructura urbana en las grandes metrópolis latinoamericanas. EURE (Santiago), 38(114), 35-69.

- CARMEN VICTORIA CATÁN JARA. (s. f.). ¿Tejiendo redes urbanas en ciudades intermedias o metropolización de las problemáticas urbanas?: El caso de estudio San Felipe-Los Andes (Tesis Master). Facultad de Arquitectura, Diseño y Estudios Urbanos de la Pontificia Universidad Católica de Chile, Santiago de Chile.

- CUENYA, BEATRIZ "Descentralización y política de vivienda en Argentina" en Reestructuración del estado y política de vivienda en Argentina, Cuenya y Falu Comp. CEA, Oficina de Publicaciones del CBC, UBA, Buenos Aires, Argentina, 1997.

- Dilemas y recursos de proyectos inclusivos en Pequeñas Ciudades. Reflexiones e ideas del seminario internacional sobre Río Tica San. Experiencia de Gestión Pública y participación comunitaria en proyectos urbanos y sociales en ciudades Latinoamericanas. (2013). Córdoba, Río Ceballos: Facultad de Arquitectura, Urbanismo y Diseño de la Universidad Nacional de Córdoba.

- Documento Base de Análisis Territorial de la Ciudad de Unquillo. Análisis y diagnóstico sobre la realidad demográfica, socio-económica, productiva e institucional de la Ciudad como insumo principal para la elaboración de una Propuesta Territorial de Promoción del Empleo. Julio, 2014

- DUCCI, M. (2002), "Area Urbana de Santiago 1991-2000: expansión de la industria y la vivienda", Eure, vol. 28, núm. 85, pp. 187-207.

- DUCCI, MARÍA ELENA. (2000). "Area Urbana de Santiago 1991-2000: expansión de la industria y la vivienda", Eure, vol. 28, núm. 85, pp. 187-207., 28.

- GUSTAVo MUNIZAGa VIGIL. (2000). Diseño urbano: teoría y método (2a. ed.). Ediciones Universidad Católica de Chile.

- JANOSCHKA, M. (2002). El nuevo modelo de la ciudad latinoamericana: fragmentación y 
privatización. EURE (Santiago), 28(85), 11-20. https://doi.org/10.4067/S0250-71612002008500002

- JAVIER HERNANDO MUÑOZ REYES. (2017). Mutaciones Urbanas Estrategias de diseño para ciudades intermedias en proceso de metropolización. Universidad Nacional de Colombia Facultad de Artes, Maestría en Diseño Urbano Bogotá D. C., Colombia, Bogota, Colombia.

- SCHTEINGART, M. (1989). Dinámica poblacional, estructura urbana y producción del espacio habitacional en la zona metropolitana de la ciudad de México. Estudios Demográficos y Urbanos, 521-548.

- SCHTEINGART, M. (1991). Producción habitacional en la Zona Metropolitana de la Ciudad de México (1960-1987). Espacio y vivienda en la Ciudad de México, El Colegio de México.

- TERÁN, FERNANDO DE. (1974). I Curso de Planificación territorial. En Problemas de forma y estructura urbanas. Madrid.

- TERÁN, FERNANDO DE. (1982). El problema Urbano. Barcelona: Salvat editores.

- Un primer triunfo contra la voracidad inmobiliaria | ECOS Córdoba | Colectivo de Comunicación. (s. f.). Recuperado 2 de noviembre de 2017, a partir de http://ecoscordoba.com.ar/un-primer-triunfo-contrala-voracidad-inmobiliaria/

- WEBBER, M. M. / DYCKMAN, J. W. / FOLEY, D. L. / GUTTENBERG, A. Z. / WHEATON, W. L. C. I BAUER WURSTER, C. (1974). Indagaciones sobre la estructura urbana. Barcelona: GUSTAVO GILI, $\mathrm{S}$. 